\title{
Carbon-Arc Light as the Electric Light of 1870
}

\section{Amelia Carolina Sparavigna'}

${ }^{1}$ Department of Applied Science and Technology, Politecnico di Torino, Italy

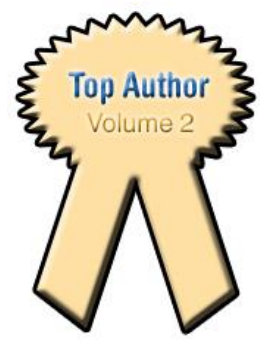

\begin{abstract}
When asked to define the electric light, we immediately think of the artificial lighting produced by incandescent and gas-discharge lamps. But in the past, the electric lamps had a rather different form. About 1870, electric lighting was based on carbon-arc devices powered by magneto-electric generators. We find an interesting and detailed description of this technology in an essay written by Jacob Abbott, an American writer of children's books, and published by Harper's Magazine in the August Issue of that year. From this Abbott's essay, we start our discuss of the electric lighting system of the 19th century.
\end{abstract}

Keywords: History of Physics, History of Engineering, Carbon-Arc Light, Electromagnetism.

\section{Introduction}

We can define the electric light as the illumination system based on lamps producing light by the flow of electric current. This is the common form of artificial lighting in our society, with two main families of devices: incandescent lamps, with light given by a filament heated by electric current, and gas-discharge lamps, which produce light by an electrical discharge through an ionized gas. However, as we will discuss in this paper, during the 19th century the electric lamps had a rather different form.

About 1870, the electric illumination was based on carbon-arc lamps and magneto-electric devices. We can outline the main features of this technology using the articles in magazines and journals of that period. An essay is quite relevant for this purpose, because it is a perfect account of the situation; it is entitled "The Electric Light" and was published in the August 1870 Issue of the Harper's Magazine, one of the oldest literary and opinion periodicals in the United States. This essay was written by Jacob Abbott (1803-1879), a prolific author of juvenile fiction that devoted some of his works to the popularization of science [1].

The Harper's Magazine was launched in June 1850 by Harper \& Brothers, publisher in New York City, as the Harper's New Monthly Magazine. The magazine was well known during its early years, for the serialization of great English novels and for the fine quality of its own essays. Harper's was also the first American periodical to introduce the extensive use of woodcut illustrations [2]. The aim of the publisher was that of giving to the "great mass of the American people, an immense amount of useful and entertaining reading matter" [3]. When Henry Mill Alden assumed the editorship in 1869 - he was editor for 50 years, until 1919 - Harper's steered away from mass popularity and became a selected magazine [3]. From 1870 to 1920 , its important essayists included Henry James and Mark Twain. On science and technology, some essays were written by Jacob Abbott, who contributed on several other subjects too.

Reading "The Electric Light" [4], we learn that the electric illumination was based on carbon-arc lamps, which were rather different from the lamps we are using today. However, such illumination had the same fundamental problems of our lamps, that is, the need of a source of power and a network for its distribution. In the following, we report some parts from this nice Harper's essay. Well-written, the Abbott's text is connecting, in its layout, physics, engineering and the use of innovative technologies for a society that was experiencing the Second Industrial Revolution.

\section{The Abbott's essay on Electric Light}

In his paper [4], Abbott defined three different methods for producing an artificial light. He called the first the Electric Light. This light is given by passing an electric current "across a break of continuity in a circuit - the break being formed by two points of charcoal, connected respectively with positive and negative poles, and brought to within a short distance of each other". That is, the electric light is that created by a carbon-arc lamp. The second is the Lime or Calcium Light, also known as the Drummond Light. This light is produced by projecting an oxyhydrogen flame upon a small piece of lime, which raises its temperature becoming intensely luminescent. The third light is the 
Magnesium Light, which is used for photographic purposes.

It is only about the first of these three lights that Abbott writes: the electric light produced by the voltaic arc between charcoal tips.

Abbott starts his article telling that there are several forms and methods of arrangement of the apparatus used for lighting. But, in any case, the essential things are the same. 1: There must be a battery, or other means, for inducing and maintaining a constant flow of electricity. 2: There must be conductive wires leading to the small charcoal cylinders where light is produced. 3: There must be an apparatus for moving one of the charcoal cylinders to keep the distance between the two tips the same. The writer explains that to "accomplish this last object was for a long time a great difficulty. But, without it - that is, without some method of keeping the break in the circuit always the same - the intensity of the light would, of course, constantly vary. And it was necessary, moreover, that the movement should be automatic - that is, that the increasing distance between the points, as the extremities were gradually burned away, should correct itself - and not be dependent on a mechanism controlled by other means" [4].

An engraving illustration, reproduced in the left part of Figure 1, gives in a simple form the method used to control the voltaic arc. The principle is that the nearer the charcoal tips are to each other the more abundant is the flow of electricity between them. A more abundant flow of electricity along the conducting wire produces a more powerful magnetic field in the iron rod or bar which the wire is made to encompass. "It is obvious that this gives us the power to regulate the distance between the points, by connecting one of them with an electro-magnet, and arranging the apparatus in such a manner that the narrowing of the interval shall increase the power of the electro-magnet, and thereby draw the point away, while increasing the interval shall weaken the magnet, and so allow the point to be brought up nearer by means of a counterpoise" [4]. In Reference 5 , we find that in the Figure 1 it is represented the apparatus that served as a basis for numerous other combinations and that was developed by Henri Adolphe Archereau (1819-1893), a French scientist. Archereau's lamp was one of the oldest carbon-arc lamps, which dates back as far as 1848 [6].

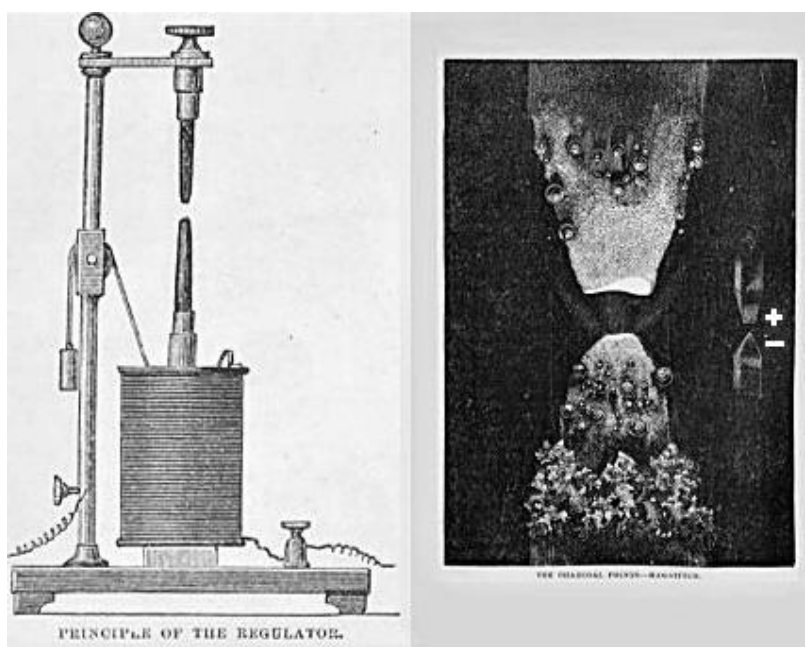

Figure 1: Reproduction of the engraved illustrations showing the carbon-arc lamp and its "points" [4].

In the Figure 1, we see the lower charcoal cylinder held in an iron tube, which is set into an electromagnetic coil. This tube can move up and down within the coil, being in equilibrium between the attractive force exerted by the coil and the weight passing over the pulley and acting as a counterpoise. We have then that, "on an increase of the distance between the points, the magnetic force, which tends to draw the lower cylinder down, is diminished, and the counterpoise raises it up. But, as soon as it approaches the upper point again, the flow of electricity is increased, the electro-magnet receives a fresh accession to its power, and the cylinder is drawn down again. In describing this contrivance, inasmuch as we are obliged to speak of these two forces separately, and to describe the operation of each in its turn, the impression might easily be left on the mind of the reader that the result would be a series of oscillations, which would be anything but indicative of steadiness in the light. But it is found in practice ... that the result is a steadily maintained equilibrium. In other words, the mechanism acts, practically, not in bringing the charcoal point back to its place when it gets out of it, but in preventing it from getting out of its place at all" [4].

In the right part of Figure 1, we see the two points of electrodes after used for a while. Abbott explains that the necessity for a constant regulation of the distance between charcoal tips is because the current is causing a gradual consumption of charcoal at the positive pole. This is "occasioned partly by the combustion of it, and partly by the transmission of incandescent particles through the air to the negative pole" [4]. In the Figure 1, the "luminous globules seen attached to the cones are the results of the fusion of earthy impurities contained in the charcoal" [4]. The gradual wasting of the tips would gradually increase the distance between them, and therefore there is the necessity of a regulation. Let us 
remember that charcoal is a material consisting of carbon and ashes, obtained by removing water and other volatile constituents from animal and vegetation substances, by means of a slow pyrolysis. Then, it is usually an impure form of carbon.

After the description of the carbon-arc lamp, Abbott discussed the supply of the needed electric current. "To produce this light there must be a constant and powerful electric current, and to induce and sustain this requires the constant expenditure of force in some other form. In the case of an ordinary galvanic battery, the force is supplied by the consumption of the zinc; but, by means of a magneto-electric arrangement - that is, an arrangement for the development of electricity by means of a rapid succession of magnetic changes produced through the revolution of a series of electro-magnets within a system of permanent magnets - the force is supplied by a steam-engine, or by the muscular power of a man" [4]. The principle on which a magneto-electric machine, like that of the French company Alliance, is created is the following: "when a bar of iron changes its magnetic state, a current of electricity is instituted, during the moment of the change, in a conducting wire passing across the bar at right angles. Thus, if a short, round bar of iron is wound with an iron wire, the two ends of the wire being left free, and the coil or bobbin, as the French call it, thus made is brought suddenly up to any strong magnet, an electric current is for the instant induced in the wire, which may be made manifest through proper observations, by means of the two ends. If now the bobbin be as suddenly withdrawn, another current in a contrary direction will be produced in the wire. ... The machine, then, is simply a mechanical arrangement for causing a great number of such coils as are above described alternately to approach to and recede from the poles of powerful magnets, in very rapid succession" [4]. In another engraving (see the Figure 2 ), the magneto-electric generator is shown.

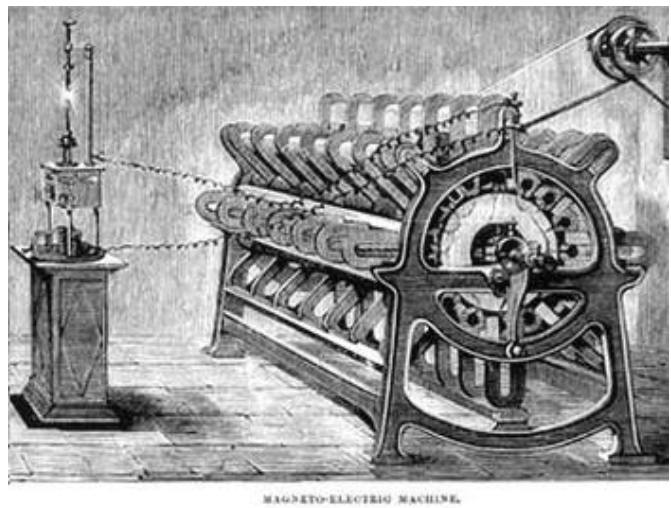

Figure 2: Reproduction of the engraved illustration showing the magneto-electric machine [4]. On the left of this image, we can see the carbon-arc lamp.

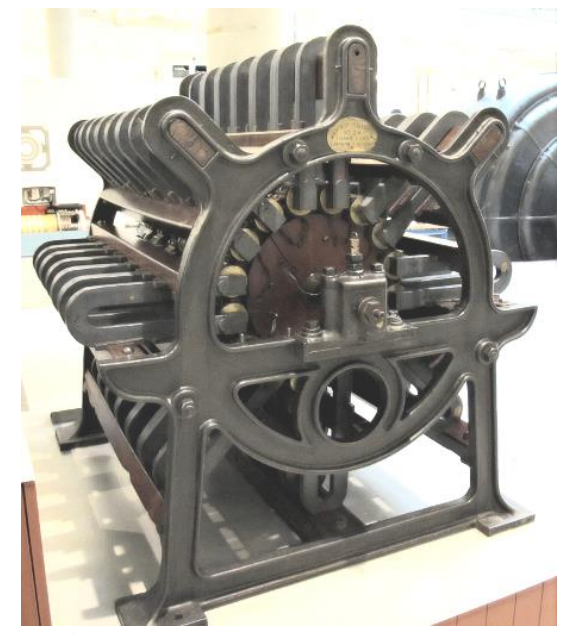

Figure 3: A photograph of the magneto-electric Alliance machine of 1870 (Courtesy: Wikipedia).

The machine illustrated in the Figure 2 (see a photograph in Figure 3) has eight ranges of magnets arranged around a hollow cylinder, with the poles turned toward the axis of the cylinder. There are seven of these magnets in each range. In the center, there is a revolving cylinder, and, upon this cylinder, we have a set of coils. "The precise arrangement of the mechanism connected with these coils cannot be fully explained. All that it is necessary, however, for the reader to understand is that they are so placed that on causing the inner cylinder to revolve, the ends of the bars which form the cores of the bobbins are brought in rapid succession into close proximity to the poles of the magnets, alternately approaching to and receding from them with great rapidity. The consequence is that a series of electrical impulses is given in the wires coiled around the bars, each impulse being in the opposite direction from the one preceding it. These currents, almost instantaneous in respect to duration, succeed each other with inconceivable rapidity - the rapidity depending on the speed of the rotation of the cylinder bearing the bobbins" [4].

Of course, it is necessary a high speed, because the light in carbon-arc lamps only shines while the current is passing: "a slow motion of the coils over the poles of the magnet would produce only a series of flashes, with perceptible intervals between them. It is found that by giving the cylinder a speed sufficient to produce about two hundred electric impulses in a second, the eye can no longer take cognizance of the interruptions, and the result is a uniform and continuous emission of a most intense and brilliant beam" [4].

Abbott is also telling that one "of the most curious and striking illustrations of the modern doctrine of the correlation of force is shown in this instrument by the fact that, although the central cylinder, bearing 
the bobbins, the turning of which seems to be all the work which is required to be done, is so nicely mounted, and on bearings so delicate as to call apparently for the exercise of only a very slight force to make it revolve, namely, that resulting from an almost inappreciable friction, it really requires a twohorse power to work the machine. The resistance comes from certain influences of the magnetic and electric agencies in their action upon each other, which influences have to be overcome by force, and this force is precisely that represented by the light developed at the break in the circuit. The machine is thus a contrivance for converting mechanical force into electricity, and then from electricity into light" [4].

The intense light produced by such lamps has a pointlike source, and therefore, "although the electric light rivals in brilliance that of the sun, the appearance is very different when employed for purposes of general illumination, on account of the extreme concentration of the radiant point, which makes the contrast of light and shade so sharp and decisive as to produce a very peculiar effect" [4]. As remarked by Abbott, this feature is rendering it remarkably suitable for the microscope and magic lantern. Another engraving is showing a manner of employing it for the microscope, that is, to have an "electric microscope". A galvanic battery, as shown by the jars on the floor (see Figure 4), produces the current.

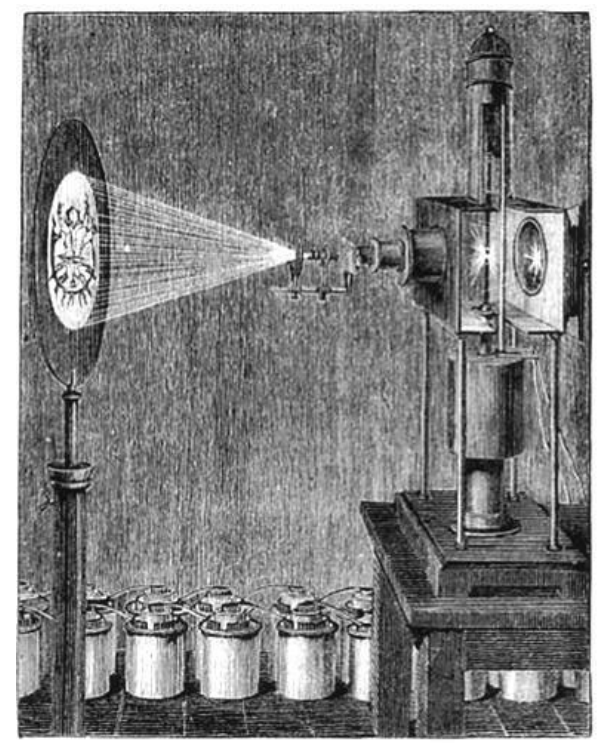

Figure 4: Reproduction of the illustration showing the electric microscope [4].

"The first attempt to employ the electric light in the construction of public works - Abbott continues - was in the building of the bridge of Notre Dame, at Paris (1853). The experiment was perfectly successful in enabling the workmen to continue their labors through the night, and in thus greatly diminishing the time required for the work. This trial was made, however, when the only mode of procuring the necessary electric power was by a battery, and the light was accordingly found to be quite expensive. Since then the much more economical mode of employing magneto-electric machines, to be worked by mechanical power, has been discovered, and the emergencies in which this light can be advantageously used are rapidly multiplying. It has been tried in mines, in caverns, on board ships, and in light-houses, and also in the construction of such works on land and in the open air as are of an urgent character requiring night labor" [4].

For what concerns the lighthouses and signal lights on board ships, Abbott tells that the electric light is "admirably adapted on account of its great penetrating power in misty and foggy states of the atmosphere. It is also found to be well fitted for the production of stage effects in operas and theatres. It is used for this purpose in Paris, and to some extent in this country. It has also been employed as a signal light from the masthead of a ship, in one of the steamers of the French line, and has thus been displayed in New York Harbor, attracting great attention from all who beheld it. The probability is that the employment of it for these and other uses will greatly increase; and it is by no means certain that it may not in the end be found to be the most effective and economical mode of illuminating large public halls" [4].

\section{Arc lamps}

Abbott is describing very well these electric lamps and their control feedback system. We know them as "arc lamps", because the light is produces by an electric arc, also called "voltaic arc", between electrodes. In 1807, Humphry Davy, famous British inventor and leading chemist of his day, invented the first arc lamp. He constructed it, using a battery of 2,000 cells to create a 4-inch arc between two charcoal sticks [7]. He mounted his electrodes horizontally and noted that, because of the strong convection flow of air, the arc formed the shape of an arch. He coined the term "arch lamp", which became "arc lamp" when the device came into common usage (see [8] and references therein).

When suitable electric generators became available, in the late 1870s, the practical and commercial use of electricity for illumination began [7]. Let us consider that, previously, electricity was a phenomenon confined to physics experiments and used for telegraphy and entertainment. The new generators powered the carbon-arc lamps invented by the Russian engineer Paul Yablochkov, in large building and street lighting of Paris and other European cities from 1878 [7]. This illumination system was used until the incandescent light superseded it, in the early 20th century. However, the carbon-arc lamps 
remained involved in limited applications, such as movie projectors, stage lighting, and searchlights, until after World War II, because of their specific properties of giving a high intensity white light with a point-like source.

Today, the term "arc lamp" refers to gas discharge lamps, which produce light by an arc between metal electrodes through an inert gas contained in a glass bulb. Neon is used commonly in fluorescent tubes, whereas Xenon is used for the lamps that replaced the carbon-arc lamps in many of their applications, such as movie projectors and searchlights [9].

\section{The electric arc}

Let us discuss the electric arc in more detail. In the Figure 1, we see that the two tips are represented with a different shape. The reason is the following, as explained in [10]. Suppose two carbon rods connected in an electric circuit, and the circuit closed by touching the tips of the rods together. When we separate the tips again, the circuit will not be broken, until the distance between the rods be not too great to prevent the formation of the voltaic arc. It is this arc between the tips, which is closing the circuit. The incandescence of the materials across which the arc is created and the arc itself form the source of light. In the Figure 5, we see the general appearance of an arc when maintained by a direct current [10] and a photograph of it [11].

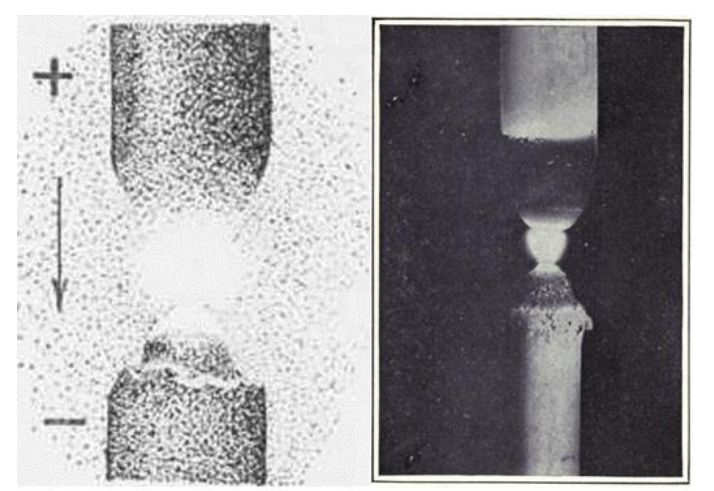

Figure 5: The arc between carbon terminals $[10,11]$.

In the Figure 5, the current is assumed as passing from the top carbon to the bottom one as indicated by arrow and signs. In the direct-current arc, most of the light is coming from the tip of the positive electrode, and in particular from the part of it known as the crater of the arc. This crater has a temperature of from 3,000 to $3,500{ }^{\circ} \mathrm{C}$ (the sublimation point of the carbon is $3642{ }^{\circ} \mathrm{C}$ ). The crater gives from 80 to $85 \%$ of the light. The negative carbon becomes pointed at the same that the positive one is hollowed out to form the crater. This electrode is also incandescent but not like the positive carbon. Between the electrodes, there is a band of violet light, the arc proper, which is surrounded by a luminous zone of a golden yellow color [10]. The arc proper does not furnish more than $5 \%$ of the light emitted when pure carbon electrodes are used. In [10], it is told that carbon rods are consumed by the passage of the current, the positive carbon being consumed about twice as rapidly as the negative.

In the Figures 1 and 5, we see a direct-current arc, that is the arc produced when the lamp is connected to a galvanic battery. If alternating current is used, the upper carbon becomes positive and negative alternately, and there is no chance for a crater to be formed, and we have that both electrodes giving off the same amount of light and being consumed at about the same rate [10].

\section{Magneto generators, lamps and society}

As described by Abbott, a magneto-electric generator, or simply "magneto", is a device that uses permanent magnets to produce alternating current. To achieve an adequate output power, the generator used many poles; usually sixteen, from eight horseshoe magnets arranged in a ring. As the flux available was limited by the magnet metallurgy [12], the only possibility was to increase the field by using more magnets. However, because this was still inadequate, extra rotor disks were stacked axially on the axle [12]. Compared to the bipolar dynamo, the several poles of the machine were providing a smoother output, which was suitable for driving arc lamps, and therefore, magneto established its small market niche as lighting generator.

In the Abbott's essay, we have that magnetos (see Figure 3) were produced by a company, named Alliance. This company was founded by the Belgian electrical engineer Floris Nollet. It was a BritishFrench company, with the name "Société de l'Alliance" [12]. The engineer Frederick Hale Holmes (c 1840-1875) continued Nollet's works on generators suitable for lighthouse illumination. The French engineer Auguste de Méritens improved magnetos further [13], replacing the rotor coils previously wound on individual bobbins, with a "ring wound" armature (see the Figure 6). This device gave larger output currents, which were more advantageous for arc lamps. Auguste de Méritens is best remembered today for his generators specifically designed for lighthouses, that were appreciated for their simplicity and reliability $[12,13]$. 


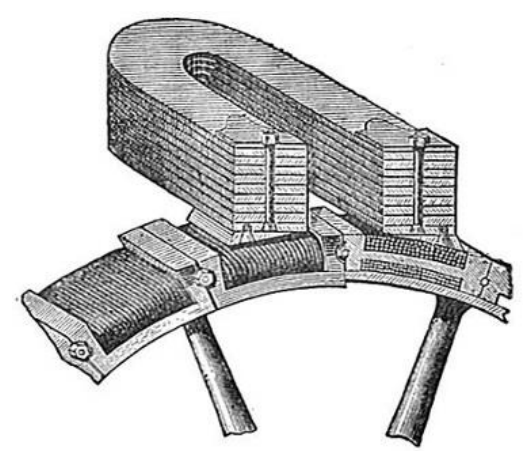

Figure 6: The French engineer Auguste de Méritens replaced the rotor coils with a ring wound armature.

In the United States, the electrical engineers began focusing on the problem of improving dynamo, to use them for arc lamps. In 1876 [14], Charles F. Brush built his first dynamo. In 1877, the Franklin Institute conducted a comparative test of dynamo systems and found that the Brush's device was the best. Brush immediately applied his dynamo to carbon-arc lighting for the Public Square in Cleveland, Ohio [8]. In 1880, Brush established the Brush Electric Company while the usage of his electric arc light spread quickly.

In the United States, patent protection of arc-lighting systems and improved dynamos proved difficult and as a result, the arc-lighting industry became highly competitive [8]. Brush's principal competitor was the team of Elihu Thomson and Edwin J. Houston, of the Thomson-Houston Electric Company. This company protected its new patent rights and had an aggressive policy of buyout and merge with competitors. In 1889, Thomson-Houston bought out the Brush Company, resolving arc lamp and dynamo patent disputes between them. By 1890, the ThomsonHouston company was the dominant electrical manufacturing company in the United States $[8,15]$. A detailed discussion of the carbon arc lamps that had been developed in this period is available in [16]. Around the turn of the century, the arc-lighting system was declining, but Thomson-Houston controlled key patents to urban lighting systems. This control slowed the expansion of the incandescent lighting system developed by Thomas Edison and his Electric Company. Conversely, Edison controlled patents on direct current generation and distribution, and this blocked further expansion of ThomsonHouston. In 1892, the two companies merged to form the General Electric Company $[8,15]$. Carbon-arc lamps were superseded by filament lamps in main roles, remaining in certain niche applications. However, arc lamps evolved in the glowing gas tubes. The neon signs were the first commercial applications of these tubes; among them, we have the Nikola Tesla's neon lamp signs that were first displayed at the 1893 Chicago World's Fair [17-19]. Later in 1897, D. McFarlan Moore gave a demonstration of his results in developing glowing lamps [20], producing "the daylight in a tube" and disclosing in this manner a lighting system never seen before. The development of neon signs in Europe is credited to Georges Claude and the first public display of a neon sign was in December of 1910 at the Paris Expo and first commercial signs were sold in $1912[18,19]$.

\section{Electromagnetic induction}

The magneto-electric generator described by Abbott is based on the electromagnetic induction, that is, the production of an electromotive force across a conductor when it is exposed to a varying magnetic field. This phenomenon is described by the Faraday's law of induction, named after Michael Faraday, a Humphry Davy's pupil, who is credited with its discovery in 1831. Joseph Henry discovered induction independently too, but Faraday was the first to publish the results of his experiments [21].

The Faraday's Law tells that when a changing magnetic field is linked with a coil, an electromotive force is induced in it. The change in magnetic field may be obtained by moving a magnet towards or away from the coil, or moving the coil into or out of the magnetic field. Of course, we find the Faraday's law in the Abbott's essay, but there is also something about the dynamical theory of electromagnetic fields developed by James Clerk Maxwell (1865) [22], when Abbott is mentioning the "influences of the magnetic and electric agencies in their action upon each other".

\section{Discussion}

The Abbott's essay on electric light assumes a greater importance if we see it positioned at the beginning of the Second Industrial Revolution. This revolution, also known as the Technological Revolution [23], was a period ranging from the second half of the 19th century until World War I. Some scholars consider that this period began after the introduction of the Bessemer steel (1856), the first inexpensive process for the mass-production of steel, and that it culminated in early factory electrification, mass production and production line [24]. During the Second Industrial Revolution, we have the expansion of railroads, of iron and steel production and of the use of machinery in manufacturing. It was also the beginning of a larger use of electricity and electrical communications, and, as remarked in [25], of the use of internal combustion engines and petroleum.

In [24], we find an assertion that we can use to conclude this article: it tells that inventions and innovations of the Second Industrial Revolution were based on the products of the engineering sciences. However, these results were deeply linked to those previously obtained by the physics and chemistry 
researches. Then, we can see the Second Industrial Revolution as based on a strong connection of academic research and education to industry and society, and this is emerging from the words of the Abbott's essay too.

\section{References}

[1] Chisholm, H. Ed. (1911). Abbott Jacob, Encyclopaedia Britannica (11th ed.), Cambridge University Press.

[2] Vv.Aa. (2014). Harper's Magazine, Encyclopaedia Britannica. [3] Chevalier, T. (2012). Encyclopaedia of the Essay, Routledge.

[4] Abbott, J. (1870). The electric light, Harper's Magazine, August Issue, pp. 245-258.

[5] Houston, E.J. \& Kennelly, A.E. (1902). Electric lighting, New York, Electrical World \& Engineer.

[6] Hospitalier, E., \& Maier, J. (1883). Modern applications of electricity, London, Paul.

[7] Vv.Aa. (2014). Arc lamp, Encyclopaedia Britannica.

[8] Vv.Aa. (2014). Arc lamp, Wikipedia.

[9] Vv.Aa. (1987). The great round world and what is going on in it, Vol.1, No. 15, February 18 . Available at www.gutenberg.org/files/ 15325/15325-h/ 15325-h.htm

[10] Vv.Aa. (1912). The electric arc, Cyclopedia of Architecture, Carpentry, and Building, Vol.7-10, American Technical Society.

[11] Child, D.D. (1913). Electric arcs: Experiments upon arcs between different electrodes in various environments and their explanation, New York, D. Van Nostrand.

[12] Vv.Aa. (2014). Magneto (generator), Wikipedia.
[13] Kennedy, R. (1903). Electrical installations, Vol.III, London, Caxton, pp. 205-206.

[14] Vv.Aa. (2014). Dynamo, Wikipedia.

[15] Noble, D.F. (1977). America by design: Science, technology, and the rise of corporate capitalism, New York, Oxford University Press.

[16] Zeidler, J. \& Lustgarten, J. (1908). Electric arc lamps, their principle, construction and working, London and New York, Harper \& Brothers.

[17] Tesla, N. (1893). On light and other high frequency phenomena, lecture before the Franklin Institute, Philadelphia, reproduced in the Twenty First Century Books, 2007.

[18] Sparavigna, A. [2007). Physics in Carnacki's investigations, arXiv:0711.4606 [physics.pop-ph].

[19] Sparavigna, A.C. (2013). Physics in Carnacki's investigations: the role of new scientific discoveries in literature, International Journal of Literature and Arts, Vol.1, No.1, pp. 11-15.

[20] Vv.Aa. (1897). Daylight seen in tubes: McFarlan Moore publicly demonstrates, The New York Times, May 28.

[21] Vv.Aa. (2014). Electromagnetic induction, Wikipedia.

[22] Maxwell, J.C. (1865). A dynamical theory of the electromagnetic field, Philosophical Transactions of the Royal Society of London, Vol.155, pp. 459-512.

[23] Muntone, S. (2014). Second Industrial Revolution. Education.com, McGraw-Hill Companies.

[24] Vv.Aa. (2014). Second Industrial Revolution, Wikipedia.

[25] Landes, D. (2003). The unbound Prometheus: Technical change and industrial development in Western Europe from 1750 to the present, New York, Cambridge University Press. 